\title{
A Simple Electrochemical Method for Nitrate Determination in Leafy Vegetables
}

\author{
Jinming Huang*, Samuel Pope and Mackenzie Willis \\ School of Mathematical and Natural Sciences, University of Arkansas at Monticello, USA
}

\begin{abstract}
A fast and easy electrochemical method for nitrate determination in leafy vegetables was developed. It is a much cheaper method compared to the HPLC method or chemiluminescence detection, the most sensitive method in determination of nitrate, which requires expensive instrumentation. A nitrate ion selective electrode was employed and the electric potentials were measured before and after a series of standard nitrate solutions added to the vegetable sample solution without any pre-treatment. After a series of electric potential measurements, the nitrate concentration initially present in the sample solution was obtained by fitting the series electric potentials measured and the corresponding standard nitrate solutions added with the Nernst equation using the SigmaPlot 13.0 software. The recovery of the method varies from $95.9 \%$ to $103.7 \%$, the low detection limit was found to be as low as about $20 \mu \mathrm{M}$, and the coefficient of variation was $3.12 \%$ for intra-day precision. The nitrate contents in several types of fresh leafy vegetables and one type of canned vegetable from a local supermarket were determined. Nitrate contents were found to be $2.58 \pm 0.24 \mathrm{mg} / \mathrm{g}$ in fresh spinach, $1.78 \pm 0.43 \mathrm{mg} / \mathrm{g}$ in fresh romaine lettuce, $1.73 \pm 0.37 \mathrm{mg} / \mathrm{g}$ in fresh iceberg lettuce, $2.14 \pm 1.18 \mathrm{mg} / \mathrm{g}$ in fresh celery, and $1.22 \pm 0.09 \mathrm{mg} / \mathrm{g}$ in canned spinach. The results agree well with results from other methods in same type of vegetables. Interference anions were also studied.
\end{abstract}

\section{Keywords}

Nitrate, Nitrite, Vegetables, Electrochemical detection

\section{Abbreviations}

NO: Nitric Oxide; $\mathrm{DI} \mathrm{H}_{2} \mathrm{O}$ : De-ionized water

\section{Introduction}

It is well known that some green leafy vegetables such as spinach and lettuce contain high levels of nitrate $\left(\mathrm{NO}_{3}^{-}\right)$[1-3], while nitrite $\left(\mathrm{NO}_{2}^{-}\right)$content in many types of fresh vegetables is much lower than nitrate [3-5]. Nitrate and nitrite in diet have long been linked to an increased risk of some cancers and methemoglobinemia called blue baby syndrome in infants $[3,6,7]$. However, recent studies in last decade suggest that dietary nitrate can significantly reduce systolic blood pressure via the nitrate-nitrite-nitric oxide (NO) pathway $[7,8]$. Dietary nitrate can be considered as a nutrient. It is estimated that vegetables contribute about $87 \%$ of nitrate dietary intake $[9,10]$. Nitrate from vegetables, whether cooked or uncooked, is absorbed very effectively resulting in an absolute nitrate bio-availability of around $100 \%$ [9]. Thus, a convenient and inexpensive method for detecting nitrate content in vegetables is of importance.

There are several methods that are currently used in the determination of nitrate. The most sensitive method for nitrite and nitrate determination is chemiluminescence detection, which can determine as low as $0.1 \mu \mathrm{M}$ nitrate in some samples, however it requires special and expensive instru- mentation, nitric oxide analyzer chemiluminescence detector $[11,12]$. Other methods for determining nitrate include the reduction of nitrate to nitrite either with a cadmium solution or passage through a copper-coated cadmium column followed by nitrite measurement by the well-known Griess assay [12-14].

Nitrate could be determined by ion selective electrode (ISE) method for which one normally needs to create a calibration curve (semi-logarithmic) to find out the nitrate concentration in the unknown sample $[15,16]$. Since nitrate is an anion so it can be determined by the ion chromatographic method [17-19]. HPLC method is also a common method in

\footnotetext{
*Corresponding author: Dr. Jinming Huang, School of Mathematical and Natural Sciences, University of Arkansas at Monticello, Monticello, AR 71656, USA, Fax: 870-460-1316

Accepted: June 20, 2019

Published online: June 22, 2019

Citation: Huang J, Pope S, Willis M (2019) A Simple Electrochemical Method for Nitrate Determination in Leafy Vegetables. J Hum Nutr 3(1):67-71
} 
the determination of nitrate in foodstuffs $[20,21]$. An UVVis spectroscopic method, either based on deconvolution of UV spectra of a number of references to reconstitute the UV spectrum of an unknown sample to determine nitrate concentration or based on the quantitative reaction of nitrate with 2-sec-butylphenol to form a yellow complex in alkaline medium which has maximum absorbance at $418 \mathrm{~nm}$ has also been used [22,23]. These methods either need special pretreatment, such as converting nitrate to nitrite then determine nitrite content, or reacting with special reagents to generate a colored compound, or need special and expensive instrumentations such as chemiluminescence detection and HPLC.

Here, we developed a simple electrochemical method that requires only a potentiometer ( $\mathrm{pH}$ meter) and a nitrate ion selective electrode to determine nitrate in green leafy vegetables. No special pre-treatment for vegetable samples and no chemical reaction with any reagents needed. Almost any research lab can afford to perform this measurement. We determined nitrate content in fresh spinach, fresh romaine lettuce, fresh iceberg lettuce, fresh celery, and canned spinach obtained from a local supermarket.

\section{Experimental Procedures}

All vegetables were purchased from a local supermarket. All chemicals were purchased from Sigma-Aldrich Chemical Company (St. Louis, MO, USA) unless otherwise indicated.

\section{Sample preparation}

For spinach (Spinacia oleracea), iceberg lettuce (Lactuca sativa), and romaine lettuce (Lactuca sativa L. var. longifolia), all edible parts were used in preparing the juice; for celery (Apium graveolens), only edible stalks were used in preparing the juice. Eighty grams of any of the above fresh vegetable were weighed and washed with de-ionized water $\left(\mathrm{DI} \mathrm{H}_{2} \mathrm{O}\right)$

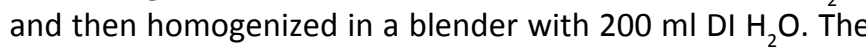
homogenized mixture was then filtered through cheesecloth to remove the solid residue and the juice volume was measured and recorded.

\section{Nitrate measurement}

A nitrate ion selective electrode (OAKTON Instruments, Inc., Vernon Hills, IL, USA) was used to determine nitrate concentration in vegetable juice samples using the standard addition method. The nitrate ion selective electrode (ISE) consists of an electrode body containing a liquid internal filling solution in contact with a gelled organophilic membrane containing a nitrate ion exchange. When the membrane is in contact with a solution containing free nitrate ions, an electric potential develops across the membrane. This electric potential is measured against a reference electrode with constant potential using a potentiometer. Since very high concentrations of nitrate were present in all tested vegetables, sample juices were diluted 100 times with $\mathrm{DI} \mathrm{H}_{2} \mathrm{O}$ before the determination. Briefly, $1.0 \mathrm{ml}$ vegetable juice was added to $99.0 \mathrm{ml} \mathrm{DI}$ $\mathrm{H}_{2} \mathrm{O}$ containing $0.04 \mathrm{M}\left(\mathrm{NH}_{4}\right)_{2} \mathrm{SO}_{4}$ as an ionic strength adjuster while stirring and then the electric potential was measured.

Next, a series small volume of standard $0.1 \mathrm{M} \mathrm{NaNO}_{3}$ solution ( $50 \mu \mathrm{l}, 100 \mu \mathrm{l}, 200 \mu \mathrm{l}, 400 \mu \mathrm{l}, 600 \mu \mathrm{l}$ ) were added to the sample solution and electric potential was measured after each standard nitrate addition. For example, if $100 \mu \mathrm{l}$ of $0.1 \mathrm{M} \mathrm{NaNO}_{3}$ solution is added to the sample solution (1.0 $\mathrm{ml}$ vegetable juice plus $99.0 \mathrm{ml} \mathrm{DI} \mathrm{H}_{2} \mathrm{O}$, total $100.0 \mathrm{ml}$ ), the final concentration of standard nitrate added to the sample is $99.90 \mu \mathrm{M}$. After a series of electric potential measurements, the nitrate concentration initially present in the sample solution was calculated by Global Curve Fitting the series electric potentials measured and the corresponding standard nitrate concentrations added with the logarithm equation of three parameters, Nernst equation $E=E^{0}-S^{*} \log \left(X+X^{0}\right)$, using the SigmaPlot 13.0 (Systat Software, Inc, San Jose, CA, USA), where $X$ is the standard nitrate concentration added to the sample solution $(\mu \mathrm{M})$ and $E$ is the electric potential measured $(\mathrm{mV})$ after each addition of standard nitrate solution, $\mathrm{X}^{0}$ is the nitrate concentration initially present in the sample solution $(\mu \mathrm{M}), E^{0}$ is the reference electric potential $(\mathrm{mV})$ which is a constant for a given electrode, and $\mathrm{S}$ is the electrode slope $\left(-59 \mathrm{mV}\right.$ at $\left.25^{\circ} \mathrm{C}\right) . \mathrm{X}^{0}, \mathrm{E}^{0}$ and $\mathrm{S}$ will be calculated by fitting. The nitrate content in the original raw vegetable was then converted from $\mu \mathrm{M}$ to $\mathrm{mg}$. $\mathrm{g}^{-1}$. Each sample analysis was carried out in three replications and the results of same type of vegetables were reported from five different samples (Mean $\pm S D, n=5$ ).

Nitrate contents in some vegetable samples were also determined by a chemiluminescence detector with the method described in previously published paper [11]. Briefly, an aliquot $(5 \mu \mathrm{l})$ of vegetable juice was injected into the reaction vessel of a nitric oxide analyzer chemiluminescence detector (Sievers NOA280i). This apparatus directly detects NO and can be used for nitrite and nitrate analysis under conditions where these species are converted to NO. For nitrite analysis, the reaction vessel contained $1 \% \mathrm{w} / \mathrm{v} \mathrm{KI}$ in glacial acetic acid to reduce nitrite to NO. For nitrate analysis, the reaction vessel contained a solution of vanadium (III) chloride in hydrochloric acid $(1 \mathrm{M} \mathrm{HCl})$ at $90{ }^{\circ} \mathrm{C}$ that reduces both nitrite and nitrate to NO. The nitrate concentration is thus obtained by subtracting the measured nitrite concentration from the concentration of nitrite and nitrate. The concentrations of nitrite and nitrate were determined on the basis of standard curve [11].

\section{Results and Discussion}

A series of electric potentials were measured after a series of standard nitrate solutions were added to a romaine lettuce sample solution. By fitting electric potentials measured (E) and standard nitrate concentrations added $(X)$ with the Nernst equation $E=E^{0}-S^{*} \log \left(X+X^{0}\right)$ using the software SigmaPlot 13.0, $38.25 \mu \mathrm{M}$ nitrate was found to be the initial nitrate concentration present in the sample $\left(\mathrm{X}^{0}\right), \mathrm{E}^{0}$ is 400.4 $\mathrm{mV}$, and the slope (S) was $62.83 \mathrm{mV}$ which was pretty close to $59.16 \mathrm{mV}$, the theoretical value at $25^{\circ} \mathrm{C}$. Figure 1 shows that the fitting result (red line) matched the experimental data (black dots) well. Nitrate concentration in a romaine lettuce juice sample was measured five times in a day and the results were $58.76 \mu \mathrm{M}, 57.99 \mu \mathrm{M}, 59.55 \mu \mathrm{M}, 59.17 \mu \mathrm{M}, 62.12 \mu \mathrm{M}$, so the coefficient of variation (CV) was $3.12 \%$ for intra-day precision. Table 1 shows the results for a romaine lettuce juice 
Citation: Huang J, Pope S, Willis M (2019) A Simple Electrochemical Method for Nitrate Determination in Leafy Vegetables. J Hum Nutr 3(1):67-71

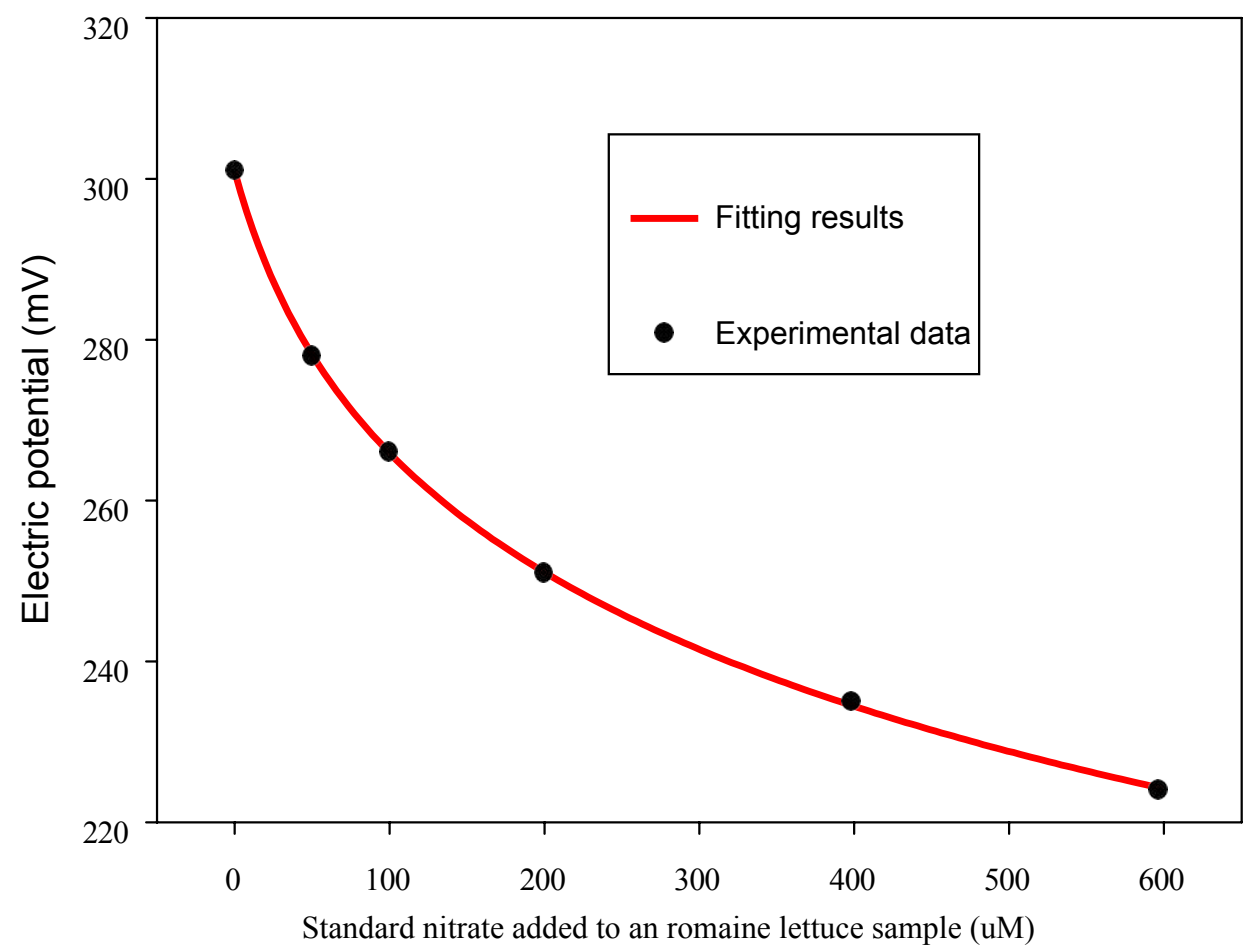

Figure 1: Sigma Plot 13.0 fitting with standard nitrate added $\left(0 \mu \mathrm{l}, 50 \mu \mathrm{l}, 100 \mu \mathrm{l}, 200 \mu \mathrm{l}, 400 \mu \mathrm{l}, 600 \mu \mathrm{l}\right.$ of $0.1 \mathrm{M} \mathrm{NaNO}_{3}$ were added to $100 \mathrm{ml}$ vegetable sample solution) and electric potential was measured after each addition of standard nitrate solution to calculate the nitrate concentration initially present in a vegetable sample. Experimental data show in black dots, fitting result shows in red line.

Table 1: Recovery test of nitrate concentration measurements (Mean $\pm S D, n=3$ ).

\begin{tabular}{|l|l|l|}
\hline Sample & Measured $\left[\mathrm{NO}_{3}^{-}\right](\mu \mathrm{M})$ & Mean Recovery (\%) \\
\hline Romaine juice & $69.1 \pm 2.9$ & N/A \\
\hline Romaine juice $+200 \mu \mathrm{M} \mathrm{NO}_{3}^{-}$ & $267.8 \pm 7.9$ & 99.4 \\
\hline
\end{tabular}

Table 2: Nitrate contents in vegetables (Mean $\pm S D, n=5$ ).

\begin{tabular}{|l|l|}
\hline Sample & {$\left[\mathrm{NO}_{3}^{-}\right](\mathbf{m g} / \mathrm{g})$} \\
\hline Fresh Spinach & $2.58 \pm 0.24$ \\
\hline Fresh Iceberg & $1.73 \pm 0.37$ \\
\hline Fresh Romaine & $1.78 \pm 0.43$ \\
\hline Fresh Celery & $2.14 \pm 1.18$ \\
\hline Canned Spinach & $1.22 \pm 0.09$ \\
\hline
\end{tabular}

sample containing $69.10 \mu \mathrm{M}$ nitrate, $200 \mu \mathrm{M}$ standard nitrate solutions was added and then the nitrate concentrations was measured again to calculate the recovery, the recovery varies from $95.9 \%$ to $103.7 \%$ with the mean recovery $99.4 \%$. Table 2 shows nitrate contents in several fresh leafy vegetables and canned spinach purchased from a local supermarket determined by this method. Nitrate contents were found to be 2.58 $\pm 0.24 \mathrm{mg} / \mathrm{g}$ in spinach, $1.78 \pm 0.43 \mathrm{mg} / \mathrm{g}$ in romaine lettuce, $1.73 \pm 0.37 \mathrm{mg} / \mathrm{g}$ in iceberg lettuce, $2.14 \pm 1.18 \mathrm{mg} / \mathrm{g}$ in celery, and $1.22 \pm 0.09 \mathrm{mg} / \mathrm{g}$ in canned spinach. Our results were mean values for same type of vegetables purchased from a local supermarket at different time (spring, fall, or winter).

Some anions interfere with the nitrate measurement. Interferences study found interference coefficients were $0.3 \%$,
Table 3: Interference test of nitrate ion selective electrode (Mean \pm $S D, n=3$ ).

\begin{tabular}{|l|l|l|}
\hline Sample & $\begin{array}{l}\text { Measured }\left[\mathrm{NO}_{3}^{-}\right] \\
(\mu \mathrm{M})\end{array}$ & $\begin{array}{l}\text { Interference } \\
\text { Coefficient }\end{array}$ \\
\hline Celery juice & $114.4 \pm 5.3$ & $\mathrm{~N} / \mathrm{A}$ \\
\hline Celery juice + $100 \mu \mathrm{M} \mathrm{NO}_{2}^{-}$ & $114.7 \pm 5.4$ & $0.3 \%$ \\
\hline Celery juice + $100 \mu \mathrm{M} \mathrm{C}_{2} \mathrm{O}_{4}^{2-}$ & $117.9 \pm 0.2$ & $3.5 \%$ \\
\hline Celery juice + $100 \mu \mathrm{M} \mathrm{Cl}^{-}$ & $119.3 \pm 2.2$ & $4.9 \%$ \\
\hline Celery juice + $100 \mu \mathrm{M} \mathrm{SO}_{4}^{2-}$ & $119.5 \pm 2.3$ & $5.1 \%$ \\
\hline Celery juice + $100 \mu \mathrm{M} \mathrm{ClO}_{3}^{-}$ & $165.5 \pm 5.6$ & $51.1 \%$ \\
\hline Celery juice $+10.0 \mu \mathrm{M} \mathrm{ClO}_{4}^{-}$ & $148.7 \pm 5.1$ & $343 \%$ \\
\hline
\end{tabular}

$3.5 \%, 4.9 \%, 5.1 \%, 51.1 \%$, and $343 \%$ for nitrite, oxalate, chloride, sulfate, chlorate, and perchlorate anions respectively when these anions were spiked to celery juice samples (Table 3). Nitrite interferes with the determination at very low level (interference coefficients was $0.3 \%$ ), considering the concentration of nitrite was at $<1.0 \mathrm{mg} / \mathrm{kg}$, which was about 1000 2000 times lower than that of nitrate in most vegetables [2426], so the interference from nitrite can be neglect. Chloride and sulfate interfere with the determination at low level (interference coefficients were $4.9 \%$ and $5.1 \%$ respectively), 
however chloride and sulfate concentrations in vegetables were much lower than that of nitrate $[27,28]$, so their interference with the determination can also be neglect. Chlorate and perchlorate interfere with the determination significantly (interference coefficients were $51.1 \%$ and $343 \%$ respectively), however chlorate and perchlorate levels in these fresh vegetables were lower than $0.025 \mathrm{mg} / \mathrm{kg}$, which was about 100,000 times lower than that of nitrate [29-32], so the interference from chlorate and perchlorate can also be neglect.

There were several reports about the determination of nitrate in vegetables using ISE method. To find out the nitrate concentration in the unknown sample, the ISE method normally need to create a calibration curve from electric potentials measured $(E)$ together with corresponding serial dilution of standard nitrate solution (semi-logarithmic curve, E vs log $X$, where $X$ is the standard nitrate concentration) and need to adjust the ionic strength in the standard nitrate solution and the sample solutions to the same level with $\left(\mathrm{NH}_{4}\right)_{2} \mathrm{SO}_{4}$, and also need to check the calibration curve every two hours, if the ambient temperature changes, a new calibration curve is needed $[1,15,16]$. It is widely known that in any quantitative analysis procedure the standard addition method normally is more accurate than the calibration curve method for a sample with complex matrix, because the standard solutions may have different signal response as compare to the unknown sample (here is the vegetable juice) that contain same concentration of the analyte (here is the nitrate), due to the fact that the composition of an unknown sample is much more complex than a standard solution. So, results obtained by comparing signals from the unknown sample and the calibration curve were not so accurate. In standard addition method, small amount of standard solution was added to the unknown solution directly for several times and the signal was monitored after each addition of standard solution, these serial measurements were under same background except that the analyte concentration is gradually increased. So the results from standard addition method normally are more accurate than that from calibration curve method. However, the standard addition method normally involves somewhat more complicated calculations. For example, in our study using Nernst equation, $E=E^{0}-S^{*} \log \left(X+X^{0}\right)$, E is the electric potential measured by a potentiometer ( $\mathrm{pH}$ meter) and $X$ is the standard nitrate concentration added to the sample, three variables $\mathrm{E}^{0}, \mathrm{~S}$, and $\mathrm{X}^{0}$ need to be calculated. In order to find out $X^{0}$, the nitrate concentration initially present in the sample, we need measure electric potential before the addition of standard nitrate solution and measure electric potentials two more times after each addition of standard nitrate. We can now find out $X^{0}$ by solving three equations. By using commercially available software SigmaPlot 13.0, we can easily calculate $X^{0}$. To obtain more accurate results we actually added standard nitrate solution five times during the measurement for each sample (Figure 1). Thus, our results actually were the average of four measurements for each sample. By adding small amount of standard nitrate solution to vegetable sample directly and measure electric potentials after each addition, the background in the vegetable sample solution will be the same except that the nitrate concentration was gradually increased. The recovery test confirmed the method is valid (the recovery of the added standard nitrate is between $95.9 \%$ and $103.7 \%$ with the mean recovery $99.4 \%$ ); while the recovery of the added standard nitrate in the calibration curve method varies from $80.4 \%$ to $113.3 \%$ with the same electrode. So, the accuracy of our method (standard addition) is better than that of the calibration curve method.

In our measurement, no special pre-treatment of the vegetable samples and no chemical reaction with any reagents are needed. We could determine nitrate at concentration as low as $-20 \mu \mathrm{M}$ and as high as $1000 \mu \mathrm{M}$ directly. We can determine nitrate at higher concentrations by diluting the sample solution with $\mathrm{DI} \mathrm{H}_{2} \mathrm{O}$. Actually during our measurements, all vegetable solutions were diluted 100 times with $\mathrm{DI} \mathrm{H}_{2} \mathrm{O}$ before start measuring electric potential. Although it is not as sensitive as the chemiluminescence detection method, since nitrate content in many types of vegetables is much higher than the detection limit $(-20 \mu \mathrm{M})$, our method would be useful for determining nitrate in most vegetables. In addition, our method is a much cheaper and easier operational method when compared with chemiluminescence detection [11]. For the same vegetable sample, nitrate content determined by our method was consistent with that determined by the chemiluminescence detection, for example, a fresh spinach sample solution was found to contain $4.028 \pm 0.049 \mathrm{mM}$ of nitrate by our method and the chemiluminescence detection found $3.986 \pm 0.094 \mathrm{mM}$ of nitrate (data obtained from a nitric oxide analyzer, Sievers NOA280i). Overall our results are comparable and agree with the results obtained from chemiluminescence detection.

\section{Conclusions}

Our electrochemical method together with software SigmaPlot $\mathbf{1 3 . 0}$ for determining nitrate in leafy vegetables is simple and inexpensive, the results agree well with chemiluminescence detection method. This method can be used to determine nitrate concentration in any aqueous sample such as vegetable samples, food samples, and water samples. The application of the software SigmaPlot 13.0 for rapid analytical determination is useful for industries.

\section{Funding}

This work was supported by Arkansas Space Grant Consortium [grant numbers 19096, 20078]; National Science Foundation and Arkansas Science \& Technology Authority [11-EPSCoR-0030, 12- EPS2-0026]; Arkansas ASSET Initiative [EPS-0701890, EPS1003970]; Arkansas Department of Higher Education [SURF grant]. This work was also partially supported by University of Arkansas at Monticello Faculty Development Grant.

\section{Conflict of Interest}

The authors state no conflicts of interest.

\section{Acknowledgement}

We thank Dr. Daniel B. Kim-Shapiro, professor of physics at Wake Forest University, for letting us use the Nitric Oxide Analyzer chemiluminescence detector (Sievers NOA280i) in determining nitrate in some vegetable samples. 


\section{References}

1. Ott-Borrelli KA, Koenig RT, Miles CA (2009) A comparison of rapid potentiometric and colorimetric methods for measuring tissue nitrate concentrations in leafy green vegetables. Hort Technology 19: 439-444.

2. Schuster PW, Lee K (1987) Nitrate and nitrite methods of analysis and levels in raw carrots, processed carrots and in selected vegetables and grain products. J Food Sci 52: 1632-1637.

3. Chan TYK (2011) Vegetable-borne nitrate and nitrite and the risk of methaemoglobinaemia. Toxicol Lett 200: 107-108.

4. Petersen A, Stoltze $S$ (1999) Nitrate and nitrite in vegetables on the Danish market: Content and intake. Food Addit Contam 16: 291-299.

5. Zhong W, Hu C, Wang M (2002) Nitrate and nitrite in vegetables from north China: Content and intake. Food Addit Contam 19: 1125-1129.

6. Greer FR, Shannon M (2005) Infant methemoglobinemia: The role of dietary nitrate in food and water. J Pediatr 116: 784-786.

7. Ashworth A, Bescos R (2017) Dietary nitrate and blood pressure: Evolution of a new nutrient? Nutr Res Rev 30: 208-219.

8. Webb AJ, Patel N, Loukogeorgakis S, et al. (2008) Acute blood pressure lowering, vasoprotective and anti-platelet properties of dietary nitrate via bioconversion to nitrite. Hypertension 51: 784-790.

9. Van Velzen AG, Sips AJ, Schothorst RC, et al. (2008) The oral bioavailability of nitrate from nitrate-rich vegetables in humans. Toxicol Lett 181: 177-181.

10. Committee on Nitrate and Alternative Curing Agents in Food (1981) The health effects of nitrate, nitrite, and N-nitroso compound, Part 1 of a 2-part Study. National Academy Press, Washington, DC, 5.41-5.52.

11. Huang J, Hadimani SB, Rupon JW, et al. (2002) Iron nitrosyl hemoglobin formation from the reactions of hemoglobin and hydroxyurea. Biochemistry 41: 2466-2474.

12. Wang QH, Yu L, Liu Y, et al. (2017) Methods for the detection and determination of nitrite and nitrate: A review. Talanta 165: 709-720.

13. Ozdestan O, Uren A (2010) Development of a cost-effective method for nitrate and nitrite determination in leafy plants and nitrate and nitrite contents of some green leafy vegetables grown in the aegean region of turkey. J Agric Food Chem 58: 5235-5240.

14. Singh P, Singh MK, Beg YR, et al. (2019) A review on spectroscopic methods for determination of nitrite and nitrate in environmental samples. Talanta 191: 364-381.

15. OAKTON Nitrate Electrodes Instruction Manual, OAKTON Instruments, Inc, Vernon Hills, IL.

16. Consalteri A, Rigato A, Clamor L, et al. (1992) Determination of nitrate in vegetables using an ion selective electrode. J Food Comp Anal 5: 252-256.

17. De Martin S, Restani P (2003) Determination of nitrates by a novel ion chromatographic method: Occurrence in leafy vegetables (organic and conventional) and exposure assessment for Italian consumers. Food Addit Contam 20: 787-792.

18. Yu BS, Chen P, Nie LH, et al. (2001) Simultaneous determination of nitrate and nitrite in saliva and foodstuffs by non-suppressed ion chromatography with bulk acoustic wave detector. Anal Sci 17: 495-498.

19. Chung SY, Kim J S, Kim M, et al. (2003) Survey of nitrate and nitrite contents of vegetables grown in Korea. Food Addit Contam 20: 621-628.

20. Hegedus O, Hegedusova A, Jakabova S, et al. (2010) Evaluation of an HPLC method for determination of nitrates in vegetables. Chromatographia 71: S93-S97.

21. Chou SS, Chung JC, Hwang DF (2003) A high performance liquid chromatography method for determining nitrate and nitrite levels in vegetables. Yaowu Shipin Fenxi 11: 233-238.

22. Nam PH, Alejandra B, Frédéric $H$, et al. (2008) A new quantitative and low-cost determination method of nitrate in vegetables, based on deconvolution of UV spectra. Talanta 76: 936-940.

23. Tanaka A, Nose N, Iwasaki H (1982) Spectrophotometric determination of nitrate in vegetable products using 2-secbutylphenol. Analyst 107: 190-194.

24. Jaworska G (2005) Nitrates, nitrites, and oxalates in products of spinach and New Zealand spinach: Effect of technological measures and storage time on the level of nitrate, nitrite, and oxalates in frozen and canned products of spinach and New Zealand spinach. Food Chem 93: 395-401.

25. Bahadoran Z, Mirmiran P, Jeddi S, et al. (2016) Nitrate and nitrite content of vegetables, fruits, grains, legumes, dairy products, meats and processed meats. J Food Comp Anal 51: 93-105.

26. Tamme T, Reinik M, Roasto M, et al. (2006) Nitrates and nitrites in vegetables and vegetable-based products and their intakes by the Estonian population. Food Addit Contam 23: 355-361.

27. Perez-Olmos R, Gabiola X, Hurtado JM (2013) Sequential potentiometric determination of nitrate and chloride in vegetables. Chemistry J 3: 81-85.

28. Florin TH, Neale G, Goretski S, et al. (1993) The sulfate content of foods and beverages. J Food Comp Anal 6: 140-151.

29. Sanchez CA, Crump KS, Krieger RI, et al. (2005) Perchlorate and nitrate in leafy vegetables of North America. Environ Sci \& Tech 39: 9391-9397.

30. Sanchez CA, Blount BC, Valentin-Blasini L, et al. (2007) Perchlorate, Thiocyanate, and nitrate in edible cole crops (Brassica sp.) produced in the lower colorado river region. Bull Environ Contam Toxicol 79: 655-659.

31. Seyfferth AL, Parker DR (2006) Determination of low levels of perchlorate in lettuce and spinach using ion chromatographyelectrospray ionization mass spectrometry (IC-ESI-MS). J Agric Food Chem 54: 2012-2017.

32. Survey Data on Perchlorate in Food - 2005-2006 and 2008-2012 Total Diet Study Results. U.S Food \& Drug Administration.

DOI: $10.36959 / 487 / 284$

Copyright: (c) 2019 Huang J, et al. This is an open-access article distributed under the terms of the Creative Commons Attribution License, which permits unrestricted use, distribution, and reproduction in any medium, provided the original author and source are credited. 